\title{
Far-red fluorescent genetically encoded calcium ion indicators
}

Rochelin Dalangin", Mikhail Drobizhev², Rosana S. Molina², Abhi Aggarwal', Ronak Patel ${ }^{3}$, Ahmed S. Abdelfattah ${ }^{3}$, Yufeng Zhao ${ }^{1}$, Jiahui $\mathrm{Wu}^{1}$, Kaspar Podgorski ${ }^{3}$, Eric R. Schreiter ${ }^{3}$, Thomas E. Hughes ${ }^{2}$, Robert E. Campbell ${ }^{1,4 *}$, Yi Shen ${ }^{1 *}$

${ }^{1}$ Department of Chemistry, University of Alberta, Edmonton, Alberta, Canada

${ }^{2}$ Department of Cell Biology \& Neuroscience, Montana State University, Bozeman, Montana, USA

3Janelia Research Campus, Howard Hughes Medical Institute, Ashburn, Virginia, USA

${ }^{4}$ Department of Chemistry, The University of Tokyo, Tokyo, Japan

${ }^{*}$ Correspondence should be addressed to Y.S. (yi.shen@ualberta.ca) or R.E.C. (robert.e.campbell@ualberta.ca) 


\begin{abstract}
Genetically encoded calcium ion $\left(\mathrm{Ca}^{2+}\right)$ indicators (GECls) are widely-used molecular tools for functional imaging of $\mathrm{Ca}^{2+}$ dynamics and neuronal activities on a single cell level. Here we report the design and development of two new far-red fluorescent GECIs, FR-GECO1a and FR-GECO1c, based on the monomeric far-red fluorescent protein mKelly. We characterized these far-red GECls as purified proteins and assessed their performance when expressed in cultured neurons. FR-GECOs have excitation and emission maxima at $\sim 596 \mathrm{~nm}$ and $\sim 644$ $\mathrm{nm}$, respectively, display large responses to $\mathrm{Ca}^{2+}\left(\Delta F / F_{0}=6\right.$ for FR-GECO1a, 18 for FR-GECO1c), and are bright under both one-photon and two-photon illumination. FR-GECOs also have high affinities (apparent $K_{d}=29 \mathrm{nM}$ for FR-GEC01a, $83 \mathrm{nM}$ for FR-GEC01c) for $\mathrm{Ca}^{2+}$, and they enable sensitive and fast detection of single action potentials in neurons.
\end{abstract}




\section{Introduction}

A property of most mammalian tissues is that they are most transparent to wavelengths of light between $\sim 600 \mathrm{~nm}$ and $\sim 1300 \mathrm{~nm}$ (the range often referred to as the "optical window") ${ }^{1,2}$. This wavelength range falls between the absorbance profile of hemoglobin, which predominates at wavelengths below $600 \mathrm{~nm}$, and the absorbance profile of water, which predominates at wavelengths greater than $1300 \mathrm{~nm}$. Due to the greater tissue transparency in this wavelength range, fluorescent probes that absorb and emit efficiently within the optical window are highly desirable for in vivo imaging. In addition, fluorescent probes with longer excitation wavelengths are associated with lower phototoxicity and autofluorescence, reduced crosstalk with green fluorescent indicators, and better spectral compatibility with blue or cyan light-activated optogenetics tools.

Realization of the advantages of fluorophores that excite and emit within the optical window has been a driving force for molecular tool engineers to shift the excitation and emission wavelengths of genetically encodable fluorophores, such as standard red fluorescent proteins (RFP) with excitation maxima $\left(\lambda_{\mathrm{ex}}\right)$ at 550 to $580 \mathrm{~nm}$ and emission $\left(\lambda_{\mathrm{em}}\right)$ at 580 to $620 \mathrm{~nm}$, into the far-red region of the spectrum. This longstanding effort has yielded a plethora of far-red FPs (Figure 1A) with $\lambda_{\mathrm{ex}}>580 \mathrm{~nm}$ and $\lambda_{\mathrm{em}}>620 \mathrm{~nm}$ (Refs. 3-12). Efforts to engineer biliverdin (BV)-binding FPs, that fluoresce at even further red-shifted wavelengths, have resulted in near infrared (NIR) FPs with $\lambda_{\mathrm{ex}}>640 \mathrm{~nm}$ and $\lambda_{\mathrm{em}}>670 \mathrm{~nm}$ (Refs. 13-15). The key difference between these two classes of genetically encodable fluorophores is that the red and far-red FPs autocatalytically form their own chromophore and are homologous with GFP, but genetically encoded NIR FPs use the biliverdin cofactor as chromophore.

Genetically encodable fluorophores can be engineered into genetically encoded indicators. One of the most important examples is the genetically encoded $\mathrm{Ca}^{2+}$ indicator (GECl) which can be used for detection and imaging of cell signalling and neuronal activities. The latest generation of red GECls for neuronal activity detection include jRCaMP1a/b, jRGECO1a, K-GECO1, and XCaMP-R, all with single-photon excitation and emission peaks outside of the optical window ${ }^{16-18}$. Among currently available RFP-based GECls, the most red-shifted variant that uses a fluorescent protein with an autocatalytic chromophore is CAR-GECO1 $\left(\lambda_{\mathrm{ex}} \sim 560 \mathrm{~nm}, \lambda_{\mathrm{em}} \sim 609 \mathrm{~nm}\right)^{19}$. Near-infrared GECl indicator NIR-GECO1 $\left(\lambda_{\mathrm{ex}} \sim\right.$ $678 \mathrm{~nm}, \lambda_{\mathrm{em}} \sim 704 \mathrm{~nm}$ ) based on the BV-binding FP mIFP has been recently reported. 
Although the spectrum of NIR-GECO1 lies well within the optical window, the molecular brightness of NIR-GECO1 is relatively $\mathrm{dim}^{20}$.

In an effort to achieve the ideal compromise between red-shifts in the excitation and emission maxima and brightness, we have undertaken the development of two bright intensiometric far-red fluorescent GECI variants, FR-GECO1a $\left(\lambda_{\mathrm{ex}} \sim 596 \mathrm{~nm}, \lambda_{\mathrm{em}} \sim 642 \mathrm{~nm}\right)$ and FR-GECO1c $\left(\lambda_{\mathrm{ex}} \sim 596 \mathrm{~nm}, \lambda_{\mathrm{em}} \sim 646 \mathrm{~nm}\right)$, based on the recently engineered far-red FP mKelly1 $\left(\lambda_{\mathrm{ex}} \sim 596 \mathrm{~nm}, \lambda_{\mathrm{em}} \sim 656 \mathrm{~nm}\right)$ and mKelly2 $\left(\lambda_{\mathrm{ex}} \sim 598 \mathrm{~nm}, \lambda_{\mathrm{em}} \sim 649 \mathrm{~nm}\right)^{12}$. These genetically encoded far-red $\mathrm{Ca}^{2+}$ indicators will open new avenues for multicolor $\mathrm{Ca}^{2+}$ imaging in combination with other optogenetic indicators and actuators, as well as functional $\mathrm{Ca}^{2+}$ imaging in deep tissue in vivo. 


\section{Results}

\section{Protein engineering}

Initial efforts to engineer a far-red $\mathrm{Ca}^{2+}$ indicator followed two parallel strategies. The first strategy was to graft key mutations for far-red fluorescence onto existing red GECls. We used R-GECO1 (Ref. 21), CH-GECO1 (Ref. 22) and K-GECO1 (Ref. 17) as templates and introduced key mutations from E2-Crimson $\left(\lambda_{\mathrm{ex}} \sim 611 \mathrm{~nm}, \lambda_{\mathrm{em}} \sim 646 \mathrm{~nm} \text {, tetrameric }\right)^{5}$, RDSmCherry $\left(\lambda_{\mathrm{ex}} \sim 600 \mathrm{~nm}, \lambda_{\mathrm{em}} \sim 630 \mathrm{~nm}\right)^{7}$, and mNeptune $\left(\lambda_{\mathrm{ex}} \sim 600 \mathrm{~nm}, \lambda_{\mathrm{em}} \sim 650 \mathrm{~nm}\right)^{4}$, respectively (Figure 1A, Supplementary Table 1). Unfortunately, complete loss of fluorescence or no substantial spectral red-shifts were observed in these designed prototypes. The second strategy was de novo engineering of a $\mathrm{GECl}$ starting from far-red FP scaffolds. However, our attempts to engineer GECl based on $\mathrm{mNeptune}^{4}$ and $\mathrm{mCardinal}{ }^{8} \mathrm{did}^{2}$ not yield fluorescent prototypes. As both mNeptune and mCardinal retained weak dimerization tendencies ${ }^{4,8,12,23}$, we suspected that the failure of these prototypes to fluoresce could be due to the circular permutation site and/or insertion site of calmodulin and its binding peptide overlapping with the oligomerization interface, possibly disrupting dimerization that was crucial to the proper folding and/or chromophore maturation of these proteins.

mKelly1 and mKelly2 are far-red FP variants of mCardinal that were engineered to have increased monomericity by a combination of deletion of the C-terminal "tail", directed evolution, and consensus design ${ }^{12}$ (Figure 1A). We rationalized that the enhanced monomericity of mKelly1 and mKelly2 might facilitate circular permutation and further engineering to create GECls. We thus circularly permuted (cp) mKelly2, the brighter of the two mKelly variants, at Thr143 (numbering according to the crystal structure for mCardinal; PDB ID: 4OQW). This designed cpmKelly2 was then used to replace the cpFusionRed RFP in K-GECO1 (Ref. 17). K-GECO1 was chosen as the starting scaffold because the use of the ckkap peptide instead of RS20 as the calmodulin binding peptide yielded a sensor with high sensitivity, strong affinity, good linearity and fast kinetics. Additionally, it is currently the only $\mathrm{GECl}$ engineered using a FP variant derived from eqFP578, from which mKelly2 was also derived (Figure 1A). This initial construct resulted in a dimly fluorescent variant we named FR-GECO0.1 (Figure 1B). Optimization of linker1 (the amino acids linking the ckkap peptide to cpmKelly2) led to the identification of an improved, but still dim, variant, FR-GECO0.2, with $\lambda_{\mathrm{ex}}=586 \mathrm{~nm}, \lambda_{\mathrm{em}}=632 \mathrm{~nm}$ and $\sim 7$-fold increase of fluorescence upon $\mathrm{Ca}^{2+}$ addition. We then 
subjected FR-GECO0.2 to eight rounds of iterative directed evolution to improve its brightness and $\mathrm{Ca}^{2+}$ response while ensuring that all the variants chosen to be used as gene templates for the next round maintained a far-red emission peak (Figure 1B). Ultimately, our efforts led to a bright and sensitive far-red GECI, FR-GECO1a, which incorporated 19 mutations relative to the initial FR-GECO0.1 gene (Supplementary Table 2). FR-GECO1a had $\lambda_{\mathrm{ex}}=596 \mathrm{~nm}, \lambda_{\mathrm{em}}=642 \mathrm{~nm}$, and exhibited a 6-fold increase in fluorescence intensity in the presence of $\mathrm{Ca}^{2+}$ (Figure 1C).

With the mKelly2-derived FR-GECO1a in hand, we attempted to incorporate mKelly1-specific mutations in an effort to achieve a slightly more red-shifted emission peak and higher photostability ${ }^{12}$. Notably, mKelly1 was engineered from mCardinal in parallel with mKelly2, and differed from mKelly2 by six mutations. To test whether these mutations could further improve FR-GECO1a, we screened a combinatorial library of FR-GECO1a containing all possible combinations of the six mKelly1-specific mutations. From this library we isolated a variant with $\lambda_{\mathrm{ex}}=596 \mathrm{~nm}$ and $\lambda_{\mathrm{em}}=646 \mathrm{~nm}$. It exhibits an 18-fold increase in fluorescence intensity in the $\mathrm{Ca}^{2+}$-bound state, which is an over 2-fold improvement relative to that of FR-GECO1a. This variant, which we termed FR-GECO1c (c for contrast) incorporated a single mutation, Tyr35Thr (numbering according to FR-GECO1a sequence, Figure 1B and Supplementary Figure 1) which is positioned in close proximity to the first gatepost residue Leu32 (Figure 1B). 

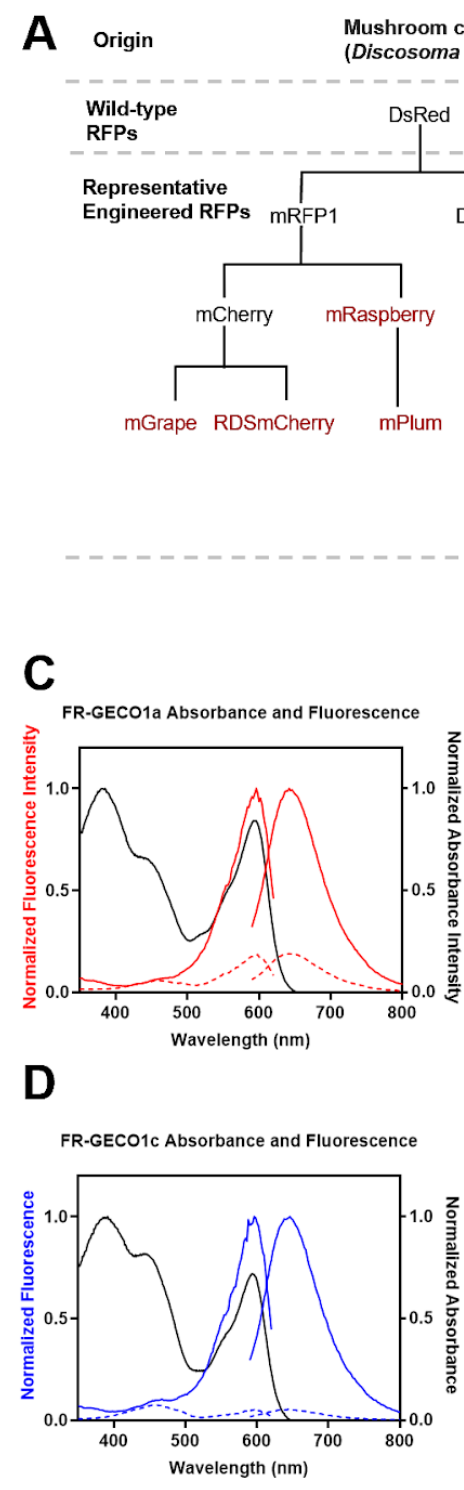

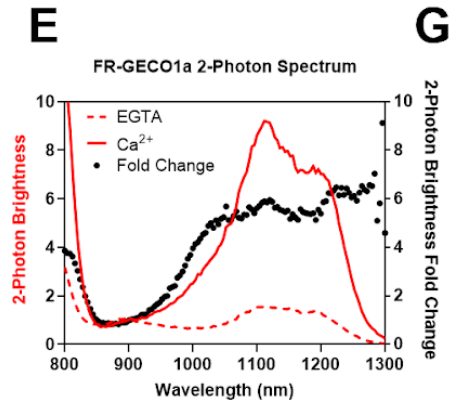

$F$

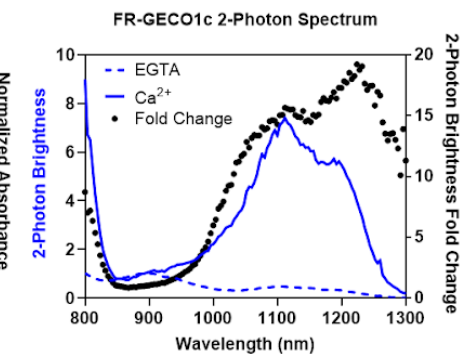

$\mathbf{G}$

H
Bubble-tip anemone (Entacmaea quadricolor)
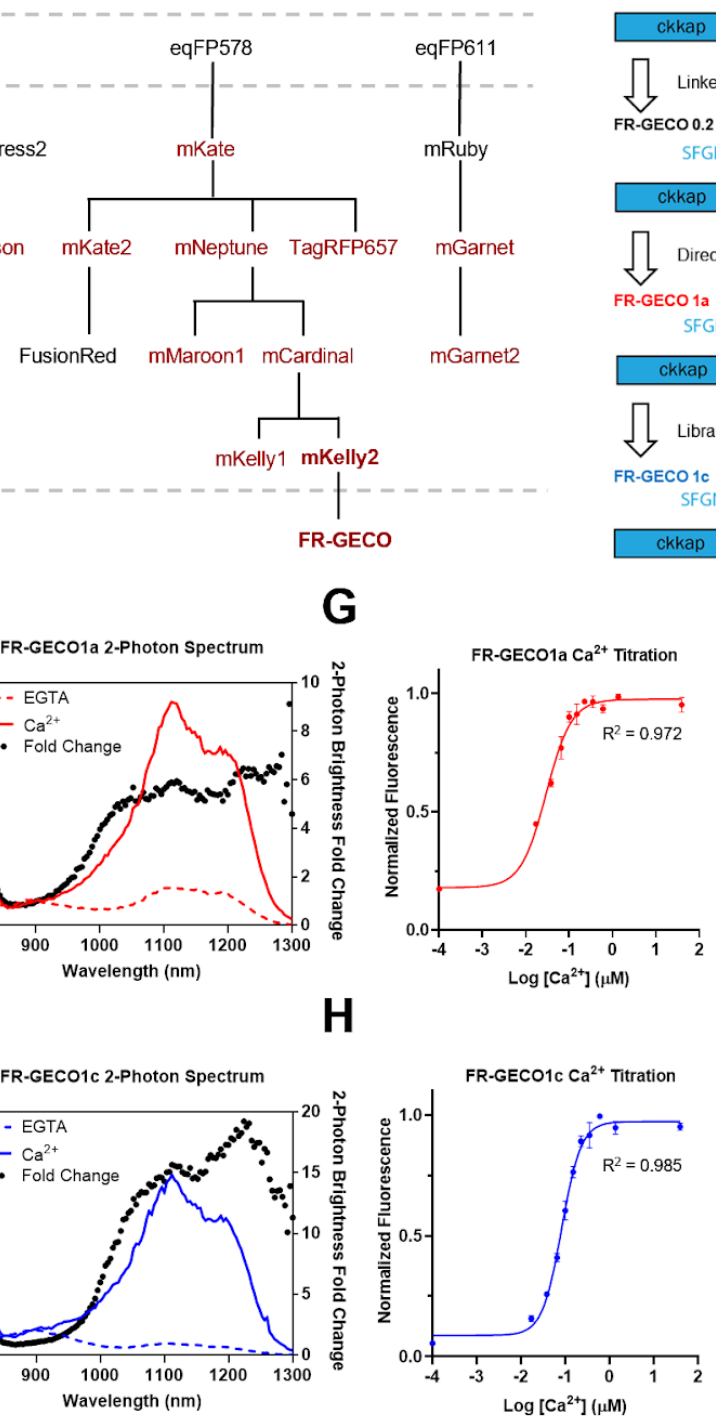

B

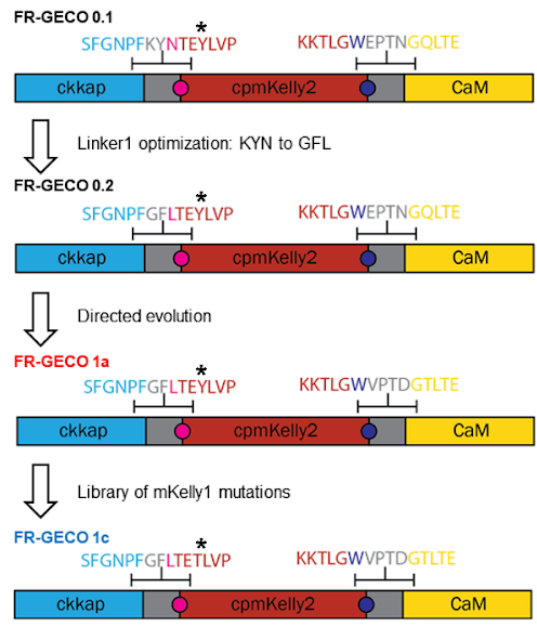

I

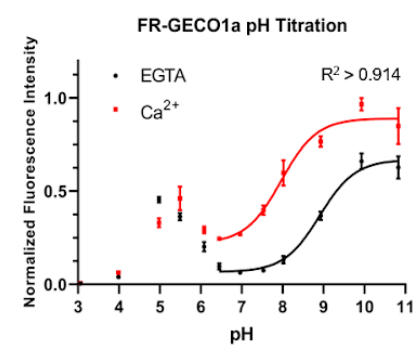

$\mathbf{J}$

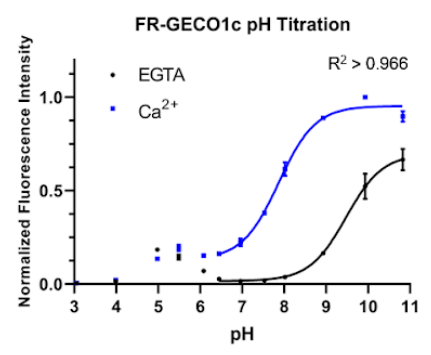

Figure 1. Engineering and characterization of FR-GECO1a and FR-GECO1c. A. Selected far-red FPs and FR-GECO genealogy. Far-red FPs $\left(\lambda_{\mathrm{em}}>620 \mathrm{~nm}\right)$ are highlighted in red. B. Schematic illustration of FR-GECO1 design and engineering. Linker residues are in grey; asterisk indicates position 35. Magenta and blue colored amino acids (and correspondingly colored circles in the schematic), represent the positions of 'gatepost' residues that define the first and last residues of cpmKelly2. Absorbance, excitation (dashed) and emission (solid) spectra of FR-GECO1a (C) and FR-GECO1c (D). Two-photon spectra and dynamic range of FR-GECO1a (E) and FR-GECO1c $(\mathbf{F}) . K_{\mathrm{d}}$ titration $(\mathrm{n}=3)$ with FR-GECO1a $(\mathbf{G})$ and FR-GECO1c $(\mathbf{H}) \cdot \mathrm{pH}$ sensitivity $(\mathrm{n}=3)$ of FR-GECO1a (I) and FR-GECO1c (J). Error bars represent S.E.M. 


\section{In vitro characterization}

To characterize the photophysical properties of FR-GECO1a and FR-GECO1c, we purified the bacterially-expressed protein. Spectral analysis of the purified proteins revealed that the $596 \mathrm{~nm}$ excitation peak of both FR-GECO1a and FR-GECO1c were slightly blue-shifted by 2 $\mathrm{nm}$ relative to mKelly2 $(598 \mathrm{~nm})$, and that the emission peaks of the FR-GECO1a (642 $\mathrm{nm})$ and FR-GECO1c $(644 \mathrm{~nm})$ were also slightly blue-shifted relative to mKelly2 (649 $\mathrm{nm}$ ) (Figure 1C, D and Table 1). The one-photon (1P) molecular brightness of FR-GECO1a (9.16) and FR-GECO1c (9.35) in their $\mathrm{Ca}^{2+}$-bound states are approximately $20 \%$ brighter than their template FP, mKelly2 (7.7) (Table 1). These results were attributed to a near doubling of the quantum yield $(Q Y, \Phi)$, which offset the effect of the indicators' smaller effective extinction coefficients $(E C, \varepsilon)$ compared to mKelly2. In the $\mathrm{Ca}^{2+}$-free and $\mathrm{Ca}^{2+}$-bound states, FR-GECO1a has ECs of 5,710 and $27,000 \mathrm{M}^{-1} \mathrm{~cm}^{-1}$, respectively, and FR-GECO1c has ECs of 4,850 and $26,500 \mathrm{M}^{-1} \mathrm{~cm}^{-1}$. The two-fold increase in the $\mathrm{Ca}^{2+}$-dependent $\Delta F / F_{0}$ of FR-GECO1c relative to FR-GECO1a (attributable to the Tyr35Thr mutation), was found to result primarily from the 2-fold smaller $\mathrm{QY}$ in the $\mathrm{Ca}^{2+}$-free state of FR-GECO1c.

Under two-photon (2P) conditions, both FR-GECO1a and FR-GECO1c had peak 2P excitation at $1112 \mathrm{~nm}$ (Figure 1E, F), with FR-GECO1a having a 25\% higher 2P molecular brightness (9.2 GM) than FR-GECO1c (7.4 GM) in the $\mathrm{Ca}^{2+}$-bound state (Table 1). Both FR-GECO1a and FR-GECO1c, in $\mathrm{Ca}^{2+}$-saturated states in vitro, were among the brightest red GECls upon 2P excitation ${ }^{24}$ (Supplementary Table 3). The optimal wavelength range for 2P excitation, with close to maximum fluorescence change, was between 1050 and $1200 \mathrm{~nm}$ (Figure 1E, F). The overall $\Delta F / F_{0}$ of FR-GECO1a and FR-GECO1C under $1 \mathrm{P}$ and $2 \mathrm{P}$ conditions were comparable. Taken together, FR-GECO1a and FR-GECO1c exhibited bright far-red fluorescence under both $1 \mathrm{P}$ and $2 \mathrm{P}$ illumination.

Consistent with other ckkap-based GECls ${ }^{17,18,25}$, static $\mathrm{Ca}^{2+}$ titrations revealed that both FR-GECO1a and FR-GECO1C have relatively high affinities for $\mathrm{Ca}^{2+}$ and Hill coefficients $\left(\mathrm{n}_{\mathrm{H}}\right)$ greater than unity (Figure 1G, H). FR-GECO1a $\left(K_{d}=32 \mathrm{nM} ; \mathrm{n}_{H}=1.49\right)$ has a substantially lower $K_{d}$ and $n_{H}$ than FR-GECO1c $\left(K_{d}=87 n M ; n_{H}=1.98\right)$. These relatively high $\mathrm{Ca}^{2+}$ binding affinities suggested FR-GECO1a and FR-GECO1c are well-suited for neuronal activity detection. Kinetic measurements revealed fast fluorescence responses from $\mathrm{Ca}^{2+}$ association 
and dissociation for both FR-GECO1a and FR-GECO1c (Table 1, Supplementary Figure 2). Specifically, FR-GECO1a (half decay time $=269 \mathrm{~ms}$ ) and FR-GECO1c (half decay time = 156 ms) are among the fastest decaying GECls with high $\mathrm{Ca}^{2+}$ affinity $^{26}$. The $\mathrm{pH}$ sensitivity measurements (Figure $1 \mathbf{I}, \mathbf{J}$ ) indicated that both FR-GECO1 variants undergo a shift in $\mathrm{pK}_{\mathrm{a}}$ upon binding $\mathrm{Ca}^{2+}$ with a $\mathrm{pK}_{\mathrm{a}}$ of $\sim 9$ in the $\mathrm{Ca}^{2+}$-free state and $\sim 8$ in the $\mathrm{Ca}^{2+}$-bound state. Both variants exhibited a small peak at $\mathrm{pH}=5$ in the $\mathrm{Ca}^{2+}$-free state and 5.5 in the bound state, suggesting multiple ionizable groups, which resembles the $\mathrm{pH}$ characterization of $\mathrm{CH}-\mathrm{GECO}$ series of red GECls ${ }^{27}$.

To test whether FR-GECOs can be photoactivated by blue light (as observed for the R-GECO family of red GECls and, to a lesser extent, K-GECO1) ${ }^{16,17,19}$, purified proteins were imaged using $561 \mathrm{~nm}\left(3.70 \mathrm{~W} / \mathrm{cm}^{2}\right)$ excitation laser with $488 \mathrm{~nm}\left(0.71 \mathrm{~W} / \mathrm{cm}^{2}\right)$ blue light laser pulses (50 ms). FR-GECO1a and FR-GECO1c were found to exhibit moderate increases in fluorescence emission with blue light illumination, in both the $\mathrm{Ca}^{2+}$-bound and $\mathrm{Ca}^{2+}$-free states (Supplementary Figure 3). However, unlike R-GECO1 $\left(\mathrm{t}_{1 / 2}=0.56 \mathrm{~s}\right.$ for $\mathrm{Ca}^{2+}$-free state) ${ }^{28}$, the photoactivation rise and decay of FR-GECOs happens within 10s of milliseconds. This fast rise and decay suggests that the photoactivation behaviour of FR-GECOs, while not desirable, could be easily distinguished from action potential-evoked GECI $\mathrm{Ca}^{2+}$ fluorescence changes, which typically happens on the timescale of seconds due to the response kinetics of GECls. 
Table 1. Photophysical characterization of FR-GECO1a, FR-GECO1c, and mKelly2.

\begin{tabular}{|c|c|c|c|c|c|}
\hline \multirow{2}{*}{ Protein Name } & \multicolumn{2}{|c|}{ FR-GEC01a } & \multicolumn{2}{|c|}{ FR-GEC01c } & \multirow{2}{*}{ mKelly2* } \\
\hline & $\mathrm{Ca}^{2+}$-free & $\mathrm{Ca}^{2+}$-bound & $\mathrm{Ca}^{2+}-$ free & $\mathrm{Ca}^{2+}$-bound & \\
\hline Excitation maxima $\lambda_{\mathrm{ex}}(\mathrm{nm})$ & \multicolumn{2}{|c|}{596} & \multicolumn{2}{|c|}{596} & 598 \\
\hline Emission maxima $\lambda_{\mathrm{em}}(\mathrm{nm})$ & \multicolumn{2}{|c|}{642} & \multicolumn{2}{|c|}{646} & 649 \\
\hline $\mathrm{Ca}^{2+}$-dependent $\Delta F / F_{0}$ & \multicolumn{2}{|c|}{$5.8 \pm 0.2$} & \multicolumn{2}{|c|}{$18.1 \pm 0.4$} & $\mathrm{n} / \mathrm{a}$ \\
\hline$K_{\mathrm{d}}(\mathrm{nM})$ & \multicolumn{2}{|c|}{29} & \multicolumn{2}{|c|}{83} & $\mathrm{n} / \mathrm{a}$ \\
\hline Apparent Hill coefficient $\left(n_{H}\right)$ & \multicolumn{2}{|c|}{1.49} & \multicolumn{2}{|c|}{1.98} & $\mathrm{n} / \mathrm{a}$ \\
\hline Apparent $\mathrm{p} K_{\mathrm{a}}$ & 8.92 & 7.96 & 9.47 & 7.88 & 5.6 \\
\hline$k_{\text {on }}\left(\mathrm{M}^{-1} \mathrm{~s}^{-1}\right)$ & \multicolumn{2}{|c|}{$9.07 \times 10^{4}$} & \multicolumn{2}{|c|}{$5.31 \times 10^{6}$} & $\mathrm{n} / \mathrm{a}$ \\
\hline Rise $t_{1 / 2}(\mu s)$ & \multicolumn{2}{|c|}{7.64} & \multicolumn{2}{|c|}{$1.31 \times 10^{-2}$} & $\mathrm{n} / \mathrm{a}$ \\
\hline$k_{\text {off }}\left(\mathrm{s}^{-1}\right)$ & \multicolumn{2}{|c|}{3.711} & \multicolumn{2}{|c|}{6.393} & $\mathrm{n} / \mathrm{a}$ \\
\hline Decay $t_{1 / 2}(\mathrm{~ms})$ & \multicolumn{2}{|c|}{269} & \multicolumn{2}{|c|}{156} & $\mathrm{n} / \mathrm{a}$ \\
\hline Extinction Coefficient $\varepsilon\left(\mathrm{M}^{-1} \mathrm{~cm}^{-1}\right)$ & 5,710 & 27,000 & 4,850 & 26,500 & 43,000 \\
\hline Quantum Yield $\Phi$ & 0.19 & 0.34 & 0.077 & 0.35 & 0.18 \\
\hline Brightness $(\times 1000)$ & 1.08 & 9.16 & 0.375 & 9.35 & 7.7 \\
\hline $\begin{array}{l}2 \mathrm{P} \text { Brightness } \mathrm{F}_{2}(\mathrm{GM}) \text {, } \\
\lambda_{\max } \text { in parentheses }\end{array}$ & $\begin{array}{c}1.56 \\
(1112 \mathrm{~nm})\end{array}$ & $\begin{array}{c}9.2 \\
(1112 \mathrm{~nm})\end{array}$ & $\begin{array}{c}0.48 \\
(1108 \mathrm{~nm})\end{array}$ & $\begin{array}{c}7.4 \\
(1112 \mathrm{~nm})\end{array}$ & $\mathrm{n} / \mathrm{d}$ \\
\hline$\Delta F / F_{0}(2 \mathrm{P}), \lambda_{\max }$ in parentheses & \multicolumn{2}{|c|}{$5.9(1112 \mathrm{~nm})$} & \multicolumn{2}{|c|}{$15.4(1112 \mathrm{~nm})$} & $\mathrm{n} / \mathrm{a}$ \\
\hline
\end{tabular}

*Values from Wannier et al. ${ }^{12}$. Errors represent S.E.M. n/a: not applicable. n/d: not determined. 


\section{Performance in cultured neurons}

The in vitro characterization of FR-GECO1a and FR-GECO1c revealed that, fluorescence colour aside, these two new GECls had properties, such as large fluorescence changes and high $\mathrm{Ca}^{2+}$ affinity, comparable to state-of-the-art GECls. Of the two indicators, we expected that FR-GECO1a might be more suitable for labelling fine subcellular neuronal processes, such as axons and dendrites, due to its brighter $\mathrm{Ca}^{2+}$-free state as shown by the characterization in vitro. On the other hand, we expected that FR-GECO1c might provide better performance for the detection of single spikes in neurons in terms of fluorescence change because of its larger $\mathrm{Ca}^{2+}$-dependent $\triangle F / F_{0}$ in vitro relative to FR-GECO1a. To evaluate the performance of FR-GECO1a and FR-GECO1c for imaging of neuronal activity, we expressed each $\mathrm{GECl}$ in dissociated rat hippocampal neurons. We observed that the fluorescence in neurons expressing either FR-GECO1 variant was evenly distributed throughout the cytosol (Figure 2A, B). Of the two indicators, FR-GECO1a did, indeed, have a brighter basal fluorescence, providing easier identification of transfected cells as well as facilitating visualization of the fine morphology of neural cells.

To evaluate indicator function, we acquired fluorescence images while delivering electric field stimuli to evoke action potentials (APs) (in trains of 1, 2, 3, 5, 10, 20, 40, 80, 120, 160 APs) (Figure 2C, D). We observed that a single stimulus elicited a $10 \% \Delta F / F_{0}$ response for FR-GECO1a ( $\mathrm{n}=81$ neurons) and a $33 \% \Delta F / F_{0}$ for FR-GECO1c ( $\mathrm{n}=68$ neurons) (Figure 2E). FR-GECO1C's response to a single stimulus is $\sim 50 \%$ higher than reported responses for jR-GECO1a and K-GECO1, suggesting that FR-GECO1c is among the most sensitive RFP-based GECls for single AP detection ${ }^{16-18}$. FR-GECO1a and FR-GECO1c showed $\Delta F / F_{0}$ of $48 \%$ and $158 \%$, respectively, upon 20 stimuli by the field electrode (Figure $2 \mathrm{~F}$ ). When evoked with 160 stimuli, neurons expressing FR-GECO1a exhibited a $\Delta F / F_{0}$ of $85 \%$ while FR-GECO1C had a $\Delta F / F_{0}$ of $220 \%$ (Figure 2 G, H). In terms of single AP response kinetics, consistent with in vitro kinetics measurement, both indicators exhibited relatively fast rise (half rise time, FR-GECO1a: $41 \mathrm{~ms}$; FR-GECO1c: $23 \mathrm{~ms}$ ) and decay (half decay time, FR-GECO1a: $0.44 \mathrm{~s}$; FR-GECO1c: $0.21 \mathrm{~s}$ ) times, with FR-GECO1c having 2-fold faster rise and decay kinetics than FR-GECO1a (Figure 2I). Overall, these results suggest that both FR-GECO1a and FR-GECO1c enable sensitive detection of neuronal activities. FR-GECO1c, 
in particular, offers exceptional single AP detection sensitivity, fast response times, and large fluorescence changes, compared to other state-of-art red GECls ${ }^{16-18}$.
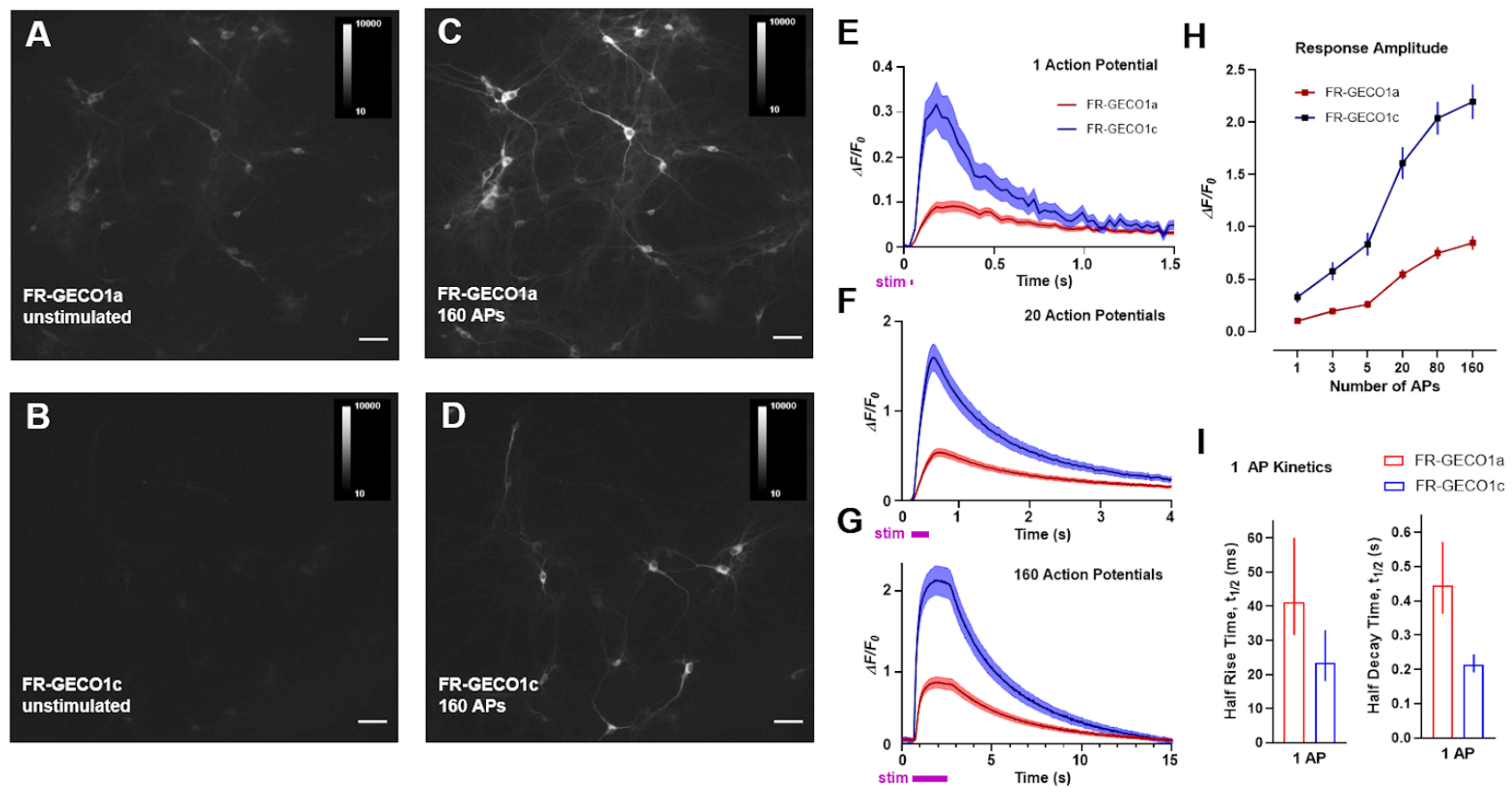

Figure 2. Performance of FR-GECO1 in cultured neurons. Representative images of neurons with FR-GECO1a at resting state (A), FR-GECO1c at resting state (B), FR-GECO1a at stimulated state (C), and FR-GECO1C at stimulated state (D). Averaged traces of FR-GECO1a (blue) and FR-GECO1c (red) recorded from neurons for 1 action potential (E), 20 action potentials $(\mathbf{F})$ and 160 action potentials $(\mathbf{G})$. Traces were normalized to baseline. Shaded areas represent S.E.M. in E, F and G. H. Averaged responses of FR-GECO1a (blue) and FR-GECO1c (red) as a function of the number of action potentials. I. Rise and decay time of FR-GECO1a and FR-GECO1c fluorescence changes induced by a single AP. Error bars represent S.E.M. in $\mathrm{H}$ and $\mathrm{I}$. ( $\mathrm{n}=68$ neurons for FR-GECO1a and $\mathrm{n}=81$ neurons for FR-GECO1c). 


\section{Discussion}

GFP- and RFP-based GECls have been extensively engineered and are widely used for imaging of cell signalling and neural activity in mammalian tissue in vivo. However, there remains a need for GECls with more red-shifted wavelengths, such as indicators with wavelengths in the far-red or near-infrared range. Indicators with longer excitation and emission wavelengths enable deeper imaging, which may be useful for imaging subcortical structures. Red-shifted indicators are also generally preferable as they provide better spectral separation from green indicators and commonly used optogenetic tools. They also show less phototoxicity and autofluorescence. Here, we have reported the engineering of FR-GECO1a/c, the first far-red fluorescent GECls that are analogous to the autofluorescent protein-based GCaMP series of $\mathrm{Ca}^{2+}$ indicators. Our initial effort to engineer a far-red $\mathrm{Ca}^{2+}$ indicator using other fluorescent protein scaffolds were unsuccessful, likely due to these scaffolds' oligomerization tendencies. On the other hand, mKelly2 is reported to be a true monomeric far-red fluorescent protein, a property which likely enabled the engineering of the first far-red fluorescence fully genetically-encoded indicator. Moreover, we expect that the cpmKelly scaffold of FR-GECO1 can serve as a template for engineering new FP-based far-red indicators for other ligands.

Both FR-GECO1 variants were also bright relative to other red GECls under 2P conditions. Their optimal 2P Ca ${ }^{2+}$-dependent $\Delta F / F_{0}$ occurs between 1050 and $1200 \mathrm{~nm}$, overlapping with the range of common tunable $2 \mathrm{P}$ lasers such as titanium-sapphire lasers ranging from 650 to $1100 \mathrm{~nm}$. When excited at $1200 \mathrm{~nm}$, FR-GECO1a and FR-GECO1c, in their $\mathrm{Ca}^{2+}$-saturated states, have very high $2 \mathrm{P}$ brightness. At this wavelength, their brightness is comparable to a handful of bright far-red FPs, such as mKates, Katushkhas, and Neptunes. Both of these sensors are much brighter upon 2P excitation at $1200 \mathrm{~nm}$ than any of the red GECls characterized so far $^{24}$ (Supplementary Table 3). Presumably, 2P microscopy at 1200 $\mathrm{nm}$ excitation will provide deeper focusing ability compared to $1100 \mathrm{~nm}$ excitation because of less scattering. Although water absorbs stronger at $1200 \mathrm{~nm}$, the depths of imaging are not too large (typically up to $200-300 \mu \mathrm{m}$ ), and this would not cause any attenuation of the laser beam. However, heating due to the laser energy absorption by water could be stronger. Improved 2P brightness of the FR-GECOs should help reduce the required laser power for excitation, and consequently, tissue heating ${ }^{29,30}$. 
NIR-GECO1 has excitation and emission peaks at 678 and $704 \mathrm{~nm}$, respectively, with a 10-fold inverted response in fluorescence intensity upon $\mathrm{Ca}^{2+}$ addition with a $K_{d}$ of $215 \mathrm{nM}$. Although not as red-shifted as NIR-GECO1, FR-GECO1 variants have higher molecular brightness, and have a positive response to $\mathrm{Ca}^{2+}$. Indicators with a positive response to their ligands are generally favoured over indicators with an inverse response due to a better signal-to-noise ratio owing to lower background fluorescence. In addition, both FR-GECO1a and FR-GECO1C offer better sensitivity $\left(\Delta F / F_{0}=10 \%\right.$ and $33 \%$ for $1 \mathrm{AP}$ and $85 \%$ and $220 \%$ for 160 APs for FR-GECO1a and FR-GECO1c, respectively) and faster kinetics (half rise time of $41 \mathrm{~ms}$ and $23 \mathrm{~ms}$ and half decay time of 440 and $210 \mathrm{~ms}$ for 1 AP for FR-GECO1a and FR-GECO1C, respectively) than NIR-GECO1 $\left(-\triangle F / F_{0}=2.3 \%\right.$ for 1 AP and $48 \%$ for 160 APs with $0.94 \mathrm{~s}$ rise time and $2.8 \mathrm{~s}$ decay time for $1 \mathrm{AP}$ and $1.3 \mathrm{~s}$ rise time and $6.5 \mathrm{~s}$ decay time for 160 APs) in neuronal activity detection.

In addition to the unique spectral profile, the FR-GECO1 series has other advantages relative to other green and red GECls. FR-GECO1c exhibits a larger $\mathrm{Ca}^{2+}$-dependent $\Delta F / F_{0}$ in vitro than most other red GECls, such as R-GECO1, K-GECO1, and XCaMP-R ${ }^{17,18,21}$. The use of ckkap peptide provides FR-GECO1a and FR-GECO1c with strong affinities for $\mathrm{Ca}^{2+}\left(\mathrm{K}_{\mathrm{d}}\right.$ $<100 \mathrm{nM}$ ), as well as large fluorescence changes and fast response times in single AP detection, similar to K-GECO1 and the XCaMP series GECI, when compared against other RS20-based indicators such as R-GECO1, and the GCaMP and RCaMP1 series ${ }^{17,18,21,28,31}$. In particular, FR-GECO1C offers better $\Delta F / F_{0}$ in single action potential detection in cultured neurons $\left(\triangle F / F_{0}=33 \%\right.$ for 1AP) than FR-GEC01a and all the other aforementioned red GECls. This excellent sensitivity of FR-GECO1c is likely due to its lower $\mathrm{Ca}^{2+}$-free state fluorescence, larger $\mathrm{Ca}^{2+}$-dependent $\Delta F / F_{0}$, and optimal affinity towards $\mathrm{Ca}^{2+}$.

As first generation sensors, FR-GECO1a and FR-GECO1c both still have room for further improvements. A general trend among FPs is that hypsochromic shifts in peak wavelengths are accompanied by reductions in quantum yield, thus limiting the brightness of available far-red and near-infrared FPs. Future versions of FR-GECO should be optimized for improved brightness to further facilitate imaging in vivo, and even faster kinetics. Given that our $\mathrm{pH}$ titrations revealed that both FR-GECO1 variants have a significantly more basic $\mathrm{pK}_{\mathrm{a}}$ relative to mKelly2 and do not exhibit their maximum brightness under physiological conditions, engineering variants with lower $\mathrm{p} K_{\mathrm{a}}$ values may also lead to improved brightness 
for imaging in tissue. Additionally, the red-shifted spectrum of FR-GECO1a/c makes them excitable with wavelengths beyond $600 \mathrm{~nm}$. Although not optimal, FR-GECO1a/c are the only non-biliverdin-binding genetically encoded $\mathrm{Ca}^{2+}$ indicator that can be excited by the widely used red helium-neon lasers ( $633 \mathrm{~nm}, \sim 12.5 \%$ of max excitation). We thus believe further red-shifted FR-GECO1a/c with better compatibility with helium-neon lasers will also be of interest to researchers.

In summary, we have developed far-red genetically-encoded indicator $\mathrm{Ca}^{2+}$ indicators, the FR-GECO series, expanding the spectral palette of available GECls that utilize non-biliverdin-binding fluorescent proteins. At its first iteration, FR-GECO1a/c showed good brightness, strong affinity for $\mathrm{Ca}^{2+}$, and good sensitivity for neuronal activity detection. In the future, we aim to improve its brightness and demonstrate its application in vivo. Furthermore, we expect that the cpmKelly2 scaffold can be used to further expand the color palette of single FP-based genetically encodable indicators for a wide range of analytes (i.e., other than $\left.\mathrm{Ca}^{2+}\right)^{32,33}$. Thus, we believe that FR-GECO1 is a valuable new addition to the GECI toolkit. 


\section{Methods}

\section{General}

Synthetic DNA oligonucleotides and double-stranded fragments (gBlocks) were sourced from Integrated DNA Technologies. CloneAmp HiFi PCR Premix and Q5 polymerase were used for high fidelity polymerase chain reactions (PCRs), and were purchased from Takara Bio USA, Inc. and New England BioLabs, respectively. Taq polymerase was purchased from Thermo Fisher Scientific. PCR products were purified by preparative agarose gel electrophoresis and extracted with GeneJET Gel Extraction Kit purchased from Thermo Fisher Scientific. Restriction enzymes and T4 DNA ligase were purchased from Thermo Fisher Scientific and used according to the manufacturer's recommended protocols. Digested PCR products were extracted with the GeneJET Gel Extraction Kit before ligation. In-Fusion HD was purchased from Takara Bio USA, Inc. and used for assembly reactions. Plasmid DNA extractions were performed with GeneJET Plasmid Miniprep Kits (Thermo Fisher Scientific). Sanger sequencing reactions were performed by the Molecular Biology Services Unit at the University of Alberta. Fluorescence measurements were performed on a Safire ${ }^{2}$ plate reader (Tecan), while absorbance measurements were collected on a DU-800 UV-Visible Spectrophotometer (Beckman).

\section{Protein Engineering}

Starting template construction. Double-stranded DNA encoding for K-GECO1 (Ref. 17), with its circularly permuted (cp) fluorescent protein replaced with cpmKelly2 (Ref. 12), was commercially synthesized with overlapping sequences with $\mathrm{pBAD} / \mathrm{HisB}$ (Thermo Fisher Scientific) in the 5' and 3' directions to facilitate insertion between the Xhol and Hindlll sites. This fragment was then assembled into pBAD/HisB vector digested with Xhol and HindIII, transformed into electrocompetent DH10B E. coli (Invitrogen), and incubated overnight on Lennox Broth (LB) agar plates supplemented with $400 \mu \mathrm{g} / \mathrm{mL}$ ampicillin (Thermo Fisher Scientific) and $0.02 \%(\mathrm{w} / \mathrm{v})$ L-arabinose (Alfa Aesar) at $37^{\circ} \mathrm{C}$. Plasmids were isolated from single colonies grown in $4 \mathrm{~mL}$ liquid LB cultures with $100 \mu \mathrm{g} / \mathrm{mL}$ ampicillin, and sequenced by Sanger sequencing. 
Plasmids for mammalian expression. Genes encoding FR-GECO1 and FR-GECO1c were amplified by high-fidelity PCR using primers that add vector homologous sequences to the 5' and 3 ' end and assembled into linearized pcDNA3.1/Puro-CAG-ASAP1 to replace the gene encoding for ASAP1 (a gift from Michael Lin, Addgene plasmid \#52519) ${ }^{34}$.

Library construction. To generate random mutagenesis libraries, mutations were introduced into the construct by error-prone PCR amplification with Taq polymerase in the presence of $\mathrm{MnCl}_{2}$ (varies; up to $0.15 \mathrm{mM}$ ) and a $1: 5$ ratio of dATP and dGTP to dCTP and dTTP. The purified PCR product was then assembled with a Xhol and Hindll digested pBAD/HisB vector. Site-directed mutagenesis libraries were generated by PCR amplification with high fidelity polymerases and primers carrying the codons for the desired mutations followed by Dpnl digestion. The NNK codon was used for complete randomization. For mutations at just one position, amplification was performed with the CloneAmp HiFi PCR Premix, while libraries with mutations at multiple locations were generated by QuikChange Lightning Multi Site-Directed Mutagenesis Kit (Agilent Technologies).

Library screening. Libraries were transformed into DH10B E. coli and cultured on LB agar plates supplemented with ampicillin and L-arabinose, as described earlier. The E. coli colonies expressing the library were then screened on the plate on the basis of fluorescence intensity using a custom imaging system described previously ${ }^{35}$. Colonies displaying the highest fluorescence intensity were then cultured in $4 \mathrm{~mL}$ liquid LB with ampicillin and arabinose overnight at $37^{\circ} \mathrm{C}$. Proteins were then extracted from cells using B-PER (Thermo Fisher Scientific) and subjected to a secondary screen by measuring their fluorescence intensities in $\mathrm{Ca}^{2+}$-free (30 mM 3-(N-morpholino)propanesulfonic acid (MOPS), $100 \mathrm{mM} \mathrm{KCl,} 10 \mathrm{mM}$ ethylene glycol-bis( $\beta$-aminoethyl ether)- $N, N, N^{\prime}, N^{\prime}$-tetraacetic acid (EGTA), $\left.\mathrm{pH} 7.2\right)$ and $\mathrm{Ca}^{2+}$ buffers (30 mM MOPS, $100 \mathrm{mM} \mathrm{KCl,} 10 \mathrm{mM} \mathrm{Ca-EGTA,} \mathrm{pH} \mathrm{7.2)} \mathrm{to} \mathrm{determine} \mathrm{their}$ $\mathrm{Ca}^{2+}$-dependent $\Delta F / F_{0}$. Plasmids for variants showing the largest $\mathrm{Ca}^{2+}$-dependent $\Delta F / F_{0}$ and highest fluorescence intensities were extracted, sequenced, and used as the template(s) for the next round of evolution. 


\section{In vitro characterization}

Protein expression and purification. The $\mathrm{pBAD} / \mathrm{HisB}$ plasmid carrying the gene encoding for the protein of interest was transformed into electrocompetent $\mathrm{DH} 10 \mathrm{~B} E$. coli and grown on solid media. Single colonies from the transformed bacteria were then used to inoculate $4 \mathrm{~mL}$ of a starter culture supplemented with ampicillin and L-arabinose that was then shaken at 225 rpm in $37^{\circ} \mathrm{C}$ overnight. The starter culture was added to $500 \mathrm{~mL}$ of LB with $100 \mu \mathrm{g} / \mathrm{mL}$ ampicillin and the culture was shaken at $37^{\circ} \mathrm{C}$. After $4 \mathrm{~h}, 0.02 \%$ L-arabinose is added to induce expression, and the culture is shaken for another $4 \mathrm{~h}$ at $37^{\circ} \mathrm{C}$ before harvesting the bacteria by centrifugation. Bacteria were then resuspended in $1 \times$ TBS $(50 \mathrm{mM}$ Tris- $\mathrm{HCl}, 150$ $\mathrm{mM} \mathrm{NaCl}, \mathrm{pH}$ 7.5), and lysed by sonication. The lysate was clarified by centrifugation and the cleared lysate was incubated with Ni-NTA resin for at least $1 \mathrm{~h}$. Resin bound to protein was washed with TBS wash buffer (1× TBS with $20 \mathrm{mM}$ imidazole, $\mathrm{pH}$ 8.0) followed by elution with TBS elution buffer ( $1 \times$ TBS with $250 \mathrm{mM}$ imidazole, $\mathrm{pH}$ 7.8). The purified protein was then left at room temperature overnight to facilitate protein folding and chromophore maturation before concentrating and buffer exchanging into $1 \times$ TBS using $10 \mathrm{kDa}$ centrifugal filter units (Millipore). Unless noted otherwise, all steps were carried out at $4^{\circ} \mathrm{C}$ or on ice.

Brightness, Affinity, and pH-sensitivity measurement. Effective ECs of FR-GECO variants were measured using the alkali denaturation method [4]. Briefly, purified protein for each FR-GECO variant was diluted in $\mathrm{NaOH}, \mathrm{Ca}^{2+}$-free (30 mM MOPS, $100 \mathrm{mM} \mathrm{KCl}, 10 \mathrm{mM}$ EGTA, pH 7.2), and $\mathrm{Ca}^{2+}$ buffer (30 mM MOPS, $\left.100 \mathrm{mM} \mathrm{KCl}, 10 \mathrm{mM} \mathrm{Ca}-E G T A, p H ~ 7.2\right)$, and the absorption spectrum for each sample was collected. Because the same amount of protein was used for each set of measurements for each protein, the concentration of protein present in each sample can be calculated according to Beer's Law and the previously reported EC of 44,000 for the absorbance peak around $\sim 450 \mathrm{~nm}$, which corresponds to the denatured tyrosine-based chromophore ${ }^{23,36}$. Further application of Beer's Law with the calculated concentration for each variant yields the $\mathrm{EC}$ in the $\mathrm{Ca}^{2+}$-bound and $\mathrm{Ca}^{2+}$-free states. Measurements were performed in triplicate and the results were averaged. Determination of QY was performed according to previously established protocols using mKelly2 as the standard ${ }^{12,21,35}$. For each protein, a series of diluted samples were prepared in $\mathrm{Ca}^{2+}$-free and $\mathrm{Ca}^{2+}$ buffer from the samples used for extinction coefficient measurements such that the peak 
absorbance was equal to, or less than, 0.05. For each dilution series, the emission spectra were collected from 590 to $750 \mathrm{~nm}$ with an excitation wavelength of $570 \mathrm{~nm}$. The total fluorescence intensities for each dilution were integrated, plotted against the absorbance, and the slope of each line $(m)$ was calculated. Quantum yields were then calculated using the published quantum yield for mKelly2 (0.18; Ref. 12) and according to the equation:

$$
\Phi_{\text {protein }}=\Phi_{\text {standard }} \times \frac{m_{\text {protein }}}{m_{\text {standard }}}
$$

Buffers for the $K_{d}$ determination, with free $\left[\mathrm{Ca}^{2+}\right]$ ranging from zero to $39 \mu \mathrm{M}$, were prepared by mixing the appropriate volumes of $\mathrm{Ca}^{2+}$-free and $\mathrm{Ca}^{2+}$ buffers, as described previously ${ }^{37}$. Purified FR-GECO variants were diluted in these buffers and the fluorescence intensities of the protein in each solution were measured in triplicate. The readings were plotted against the free $\mathrm{Ca}^{2+}$ concentration on a logarithmic scale, and the data fitted to the Hill equation for the $K_{\mathrm{d}}$ and apparent Hill coefficient. Aliquots of a buffer containing $30 \mathrm{mM}$ trisodium citrate and 30 $\mathrm{mM}$ borax (sodium borate) were adjusted using $\mathrm{HCl}$ or $\mathrm{NaOH}$ so that their $\mathrm{pH}$ ranged from 3 to 11. Concentrated protein, as well as $1 \mu \mathrm{L}$ of either $200 \mathrm{mM} \mathrm{EGTA}$ or $\mathrm{CaCl}_{2}$ for the $\mathrm{Ca}^{2+}$-free and $\mathrm{Ca}^{2+}$ conditions, respectively, were then diluted in these buffers for a total volume of 100 $\mu \mathrm{L}$. The fluorescence intensities were measured in triplicate, and the readings were plotted against $\mathrm{pH}$. Due to the ionization events at $\mathrm{pH} \sim 5$ to 6 , only the data for $\mathrm{pH} 6.5$ to 11 were fitted to the Hill equation for the $p K_{a}$.

In vitro kinetics measurement. Rapid kinetic measurements of FR-GECO1a and FR-GECO1C in purified protein were made using an Applied Photophysics SX-20 Stopped-Flow Reaction Analyzer using fluorescence detection. The dead time of the instrument was $1.1 \mathrm{~ms}$. The excitation wavelength used was $625 \mathrm{~nm}$ with $2 \mathrm{~nm}$ bandwidth and emitted light was collected at $690 \mathrm{~nm}$ through a $10 \mathrm{~mm}$ path at room temperature. For $k_{\text {off }}$ measurements, $2 \mu \mathrm{M}$ of each FR-GECO1a and FR-GECO1c proteins in $1 \mathrm{mM} \mathrm{Ca}^{2+}(30 \mathrm{mM}$ MOPS, $100 \mathrm{mM} \mathrm{KCl}, \mathrm{pH}$ 7.2) were rapidly mixed at 1:1 ratio with $100 \mathrm{mM}$ of EGTA (30 mM MOPS, $100 \mathrm{mM} \mathrm{KCl}, \mathrm{pH} \mathrm{7.2)} \mathrm{at} \mathrm{room} \mathrm{temperature.} \mathrm{Measurements} \mathrm{were} \mathrm{taken} \mathrm{for} \mathrm{five}$ replicates. $k_{\text {off }}$ values were determined by fitting a single exponential dissociation curve to the signal decay with units of $\mathrm{s}^{-1}$, using Prism GraphPad. For $k_{\mathrm{on}}$, both variants, buffered in $30 \mathrm{mM}$ MOPS and $100 \mathrm{mM} \mathrm{KCl}(\mathrm{pH}=7.2)$, were rapidly mixed at $1: 1$ ratio with varying 
concentrations of $\mathrm{Ca}^{2+}$ produced by reciprocal dilutions of $10 \mathrm{mM}$ EGTA and $10 \mathrm{mM}$ CaEGTA by using the Calcium Calibration Buffer Kit (ThermoFisher Scientific). The slope of $k_{\text {obs }}$ was used to determine $k_{\text {on }}$ rate in the units of $\mathrm{s}^{-1} \mathrm{M}^{-1}$. Two replicates were used for each $\mathrm{Ca}^{2+}$ concentration.

Photoactivation measurement. Microdroplets of FR-GECO1a and FR-GECO1c in purified protein in either $\mathrm{Ca}^{2+}$ or $\mathrm{Ca}^{2+}$-free buffer $(\mathrm{pH}$ 7.2) were prepared using Octanol. The prepared sample was sandwiched between pre-silanized coverglass and coverslip. Using a widefield microscope each droplet was continuously illuminated with a $561 \mathrm{~nm}$ laser for $120 \mathrm{sec} .488$ $\mathrm{nm}$ laser was used for photoactivation while the $561 \mathrm{~nm}$ laser was on. The $488 \mathrm{~nm}$ laser was on for $50 \mathrm{~ms}$ with the shutters switching on at various frequencies $(0.5,1$, or $2 \mathrm{~Hz})$.

2P characterization. Experimental setup for 2P spectral measurements includes a tunable femtosecond laser InSight DeepSee Dual (Spectra Physics) coupled with a photon counting spectrofluorometer PC1 (ISS) ${ }^{24,38}$. The 2P fluorescence excitation (2PE) spectra were measured by automatically stepping laser wavelength and recording total fluorescence intensity at each step. A combination of filters, including FF01-770/SP, FF01-680/SP (both Semrock), and FGL630 long-pass (Thorlabs) was used in the left emission channel of PC1 spectrofluorometer to eliminate scattered laser light. To scale the $2 \mathrm{P}$ excitation spectra, we use a parameter called 2P molecular brightness $F_{2}(\lambda)$. This parameter depends on fractional contributions to $2 \mathrm{P}$ brightness of the anionic and neutral forms at excitation wavelength $\lambda$ and can be presented as follows:

$$
F_{2}(\lambda)=\rho_{A} \varphi_{A} \sigma_{2},{ }_{A}(\lambda)+\rho_{N} \varphi_{N} \sigma_{2},{ }_{N}(\lambda)
$$

where $\varphi$ is the fluorescence quantum yield of form $A$ or $N$, and $\sigma_{2}$ is the $2 \mathrm{P}$ absorption cross section. Since we collect fluorescence spectrum through a FGL630 long-pass filter, technically $\varphi_{N}$ only comprises a part of fluorescence originating from anionic deprotonated chromophore that appears after the excited-state proton transfer from initially excited neutral form. To obtain the $2 \mathrm{P}$ excitation spectrum in units of molecular brightness, we independently measured $\rho_{A}, \varphi_{A}$, and $\sigma_{2, A}(\lambda)$ of the anionic form for both FR-GECO1a/c in $\mathrm{Ca}^{2+}$-free and $\mathrm{Ca}^{2+}$-saturated states and normalized the unscaled $2 \mathrm{P}$ spectrum to the product $\rho_{A} \varphi_{A} \sigma_{2^{\prime}{ }_{A}}(\lambda)$. 
The cross section $\sigma_{2}{ }_{A}(\lambda)$ was measured at the wavelength where the contribution of the neutral form is negligible $(\lambda=1064 \mathrm{~nm})$. This measurement was performed using Rhodamine $B$ in alkaline ethanol as a reference standard. Its cross section was measured relatively to

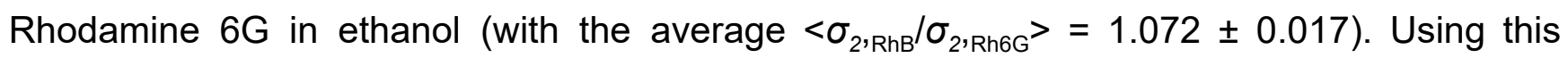
number together with the Rhodamine $6 \mathrm{G}$ cross section in ethanol $\left(\sigma_{2, \mathrm{Rh} 6 \mathrm{G}}\right)$ obtained after averaging of seven independent measurements ${ }^{38}:\left\langle\sigma_{2}\right.$, Rh6G $>=12.4 \pm 2.6 \mathrm{GM}$, cross section of Rhodamine $\mathrm{B}$ in ethanol at $1064 \mathrm{~nm}$ was calculated $\sigma_{2}, \mathrm{RhB}=13.3 \pm 2.8 \mathrm{GM}$ and used as a reference. In a modified version of previously reported method ${ }^{38}$, a total (without monochromator) 2P excited (at $1064 \mathrm{~nm}$ ) fluorescence signals / as a function of laser power $P$ were collected for both the sample and reference solutions (solutions were held in $3 \times 3 \mathrm{~mm}$ cuvettes (Starna) with maximum optical density less than 0.1). The fluorescence was collected at $90^{\circ}$ to excitation laser beam through FF01-770/SP, FGL630 Longpass, and long wave pass 561 (Edge Basic $^{\mathrm{TM}}$, Semrock) filters, using the left emission channel of a PC1 spectrofluorometer working in a photon counting mode. The power dependences of fluorescence were fit to a quadratic function $I=a P^{2}$, from which the coefficients $a_{S}$ and $a_{R}$ were obtained for the sample (index $S$ ) and reference (index R) solutions, respectively. Second, the 1P excited fluorescence signals were measured for the same samples and in the same registration conditions. In this case, a strongly attenuated radiation of a $561 \mathrm{~nm}$ line of a Sapphire 561-50 CW CDRH (Coherent) laser was used for excitation. The fluorescence power dependences for the sample and reference were measured and fit to a linear function: I $=b P$, from which the coefficients $b_{S}$ and $b_{R}$ were obtained. The $2 \mathrm{P}$ absorption cross section was then calculated as follows:

$$
\sigma_{2, S}\left(\lambda_{2}\right)=\frac{a_{S}}{a_{R}} \frac{b_{R}}{b_{S}} \frac{\varepsilon_{S}\left(\lambda_{1}\right)}{\varepsilon_{R}\left(\lambda_{1}\right)} \sigma_{2, R}\left(\lambda_{2}\right)
$$

Here, $\lambda_{1}$ is the wavelength used for $1 \mathrm{P}$ excitation $(561 \mathrm{~nm}), \lambda_{2}$ is the wavelength used for $2 \mathrm{P}$ excitation (1064 nm), $\varepsilon_{R, S}\left(\lambda_{1}\right)$ are the corresponding extinction coefficients, measured at $\lambda_{1}$. (In contrast to the one-photon characterization section, we define extinction coefficient $\left(\varepsilon_{\mathrm{S}}\right)$ here to be of a particular, anionic, form. It relates to the previously defined extinction coefficient, e.g. shown in Table 1, as follows: $\varepsilon_{S}=\varepsilon / \rho_{A}$ ) This approach allows us to automatically correct for the laser beam properties (pulse duration and spatial intensity distribution), fluorescence 
collection efficiencies for 1P and 2P modes, PMT spectral sensitivity, differences in QYs and concentrations between $\mathrm{S}$ and $\mathrm{R}$ solutions. Molecular brightness of the anionic form was then calculated as a product $F_{2}=\rho_{A} \varphi_{A} \sigma_{2, A}\left(\lambda_{m}\right)$ with the $2 \mathrm{P}$ cross section taken at spectral maximum, $\lambda_{\mathrm{m}}$, for both states of the sensor. The QYs, ECs, and fractional concentrations were all measured independently. Finally, the $2 \mathrm{P}$ excitation spectra were scaled to the calculated $F_{2}(1064 \mathrm{~nm})$ values.

\section{Imaging in cultured neuron}

Primary rat hippocampal neurons were prepared as described previously ${ }^{39}$. Cultured neurons were transfected with pCAG-FR-GECO1a and pCAG-FR-GECO1c plasmids using electroporation (Lonza Nucleofector) according to manufacturer's instructions. Prior to imaging session, transfected neurons were first washed twice with imaging buffer (145 mM $\mathrm{NaCl}, 2.5 \mathrm{mM} \mathrm{KCl}, 10 \mathrm{mM}$ glucose, $10 \mathrm{mM}$ HEPES, $\mathrm{pH}$ 7.4, $2 \mathrm{mM} \mathrm{CaCl}$ and $1 \mathrm{mM} \mathrm{MgCl}_{2}$ ), and treated with synaptic blockers (10 $\mu \mathrm{M}$ CNQX, $10 \mu \mathrm{M}$ CPP, $10 \mu \mathrm{M}$ GABAZINE, and $1 \mathrm{mM}$ MCPG). Neurons were imaged using an inverted Nikon Eclipse Ti2 microscope equipped with a SPECTRA $X$ light engine (Lumencor), a 20x objective (NA = 0.75, Nikon), and a sCMOS camera (Hamamatsu ORCA-Flash 4.0). Neurons were stimulated by field stimulation with a custom-built platinum wire electrode with a stimulus isolator (A385, World Precision Instruments). Trains of 1, 2, 3, 5, 10, 20, 40, 80, 120 and 160 APs were stimulated and fluorescence images were acquired throughout the stimulation session. Acquired images were processed with ImageJ. 


\section{Author contributions}

$Y S, R E C$ conceived the project. $Y S, R D, J W$ performed protein engineering. RD, YS, MD, $\mathrm{RSM}, \mathrm{AA}, \mathrm{RP}$ performed in vitro protein characterization. $\mathrm{YS}, \mathrm{ASA}, \mathrm{YZ}$ performed cultured cell imaging. YS, KP, ERS, TEH, REC supervised the research. YS, RD, MD, REC wrote the manuscript. All authors read and approved the final manuscript.

\section{Acknowledgments}

We thank the University of Alberta Molecular Biology Services Unit for technical support. We thank Dr. Timothy Wannier for sharing mKelly sequences. We thank Dr. Fern Sha, Rosario Valenti, and the Janelia Research Campus cell culture facility for technical assistance. Ronak Patel is a member of the Janelia Research Campus Tool Translation Team (T3); we thank the T3 for providing equipment access and technical support. This work was supported by grants from the Natural Sciences and Engineering Research Council of Canada (NSERC; RGPIN 2018 04364), the Canadian Institutes of Health Research (CIHR; FS 154310), and Janelia Visiting Scientist Program (Janelia Research Campus, HHMI).

\section{Competing interests}

The authors declare that they have no conflicts of interest.

\section{Material and data availability}

The data supporting this research are available upon request. Plasmid constructs encoding FR-GECO1a and FR-GECO1c are available through Addgene. 


\section{References}

1. Tromberg, B. J. et al. Non-invasive in vivo characterization of breast tumors using photon migration spectroscopy. Neoplasia 2, 26-40 (2000).

2. Lyons, S. K., Patrick, P. S. \& Brindle, K. M. Imaging mouse cancer models in vivo using reporter transgenes. Cold Spring Harb. Protoc. 2013, 685-699 (2013).

3. Abbyad, P., Childs, W., Shi, X. \& Boxer, S. G. Dynamic Stokes shift in green fluorescent protein variants. Proc. Natl. Acad. Sci. U. S. A. 104, 20189-20194 (2007).

4. Lin, M. Z. et al. Autofluorescent proteins with excitation in the optical window for intravital imaging in mammals. Chem. Biol. 16, 1169-1179 (2009).

5. Strack, R. L. et al. A rapidly maturing far-red derivative of DsRed-Express2 for whole-cell labeling. Biochemistry 48, 8279-8281 (2009).

6. Shen, Y., Lai, T. \& Campbell, R. E. Red fluorescent proteins (RFPs) and RFP-based biosensors for neuronal imaging applications. Neurophotonics 2, 031203 (2015).

7. Shen, Y., Chen, Y., Wu, J., Shaner, N. C. \& Campbell, R. E. Engineering of mCherry variants with long Stokes shift, red-shifted fluorescence, and low cytotoxicity. PLoS One 12, e0171257 (2017).

8. Chu, J. et al. Non-invasive intravital imaging of cellular differentiation with a bright red-excitable fluorescent protein. Nat. Methods 11, 572-578 (2014).

9. Hense, A. et al. Monomeric Garnet, a far-red fluorescent protein for live-cell STED imaging. Sci. Rep. 5, 18006 (2015).

10. Matela, G. et al. A far-red emitting fluorescent marker protein, mGarnet2, for microscopy and STED nanoscopy. Chem. Commun. 53, 979-982 (2017).

11. Bajar, B. T. et al. Fluorescent indicators for simultaneous reporting of all four cell cycle 
phases. Nat. Methods 13, 993-996 (2016).

12. Wannier, T. M. et al. Monomerization of far-red fluorescent proteins. Proc. Natl. Acad. Sci. U. S. A. 115, E11294-E11301 (2018).

13. Yu, D. et al. A naturally monomeric infrared fluorescent protein for protein labeling in vivo. Nat. Methods 12, 763-765 (2015).

14. Rodriguez, E. A. et al. A far-red fluorescent protein evolved from a cyanobacterial phycobiliprotein. Nat. Methods 13, 763-769 (2016).

15. Shemetov, A. A., Oliinyk, O. S. \& Verkhusha, V. V. How to Increase Brightness of Near-Infrared Fluorescent Proteins in Mammalian Cells. Cell Chem Biol 24, 758-766.e3 (2017).

16. Dana, H. et al. Sensitive red protein calcium indicators for imaging neural activity. Elife 5, e12727 (2016)

17. Shen, Y. et al. A genetically encoded Ca2+ indicator based on circularly permutated sea anemone red fluorescent protein eqFP578. BMC Biol. 16, 9 (2018).

18. Inoue, M. et al. Rational engineering of XCaMPs, a multicolor GECl suite for in vivo imaging of complex brain circuit dynamics. Cell 177, 1346-1360. e24 (2019).

19. Wu, J. et al. Improved orange and red $\mathrm{Ca} 2+$ indicators and photophysical considerations for optogenetic applications. ACS Chem. Neurosci. 4, 963-972 (2013).

20. Qian, Y. et al. A genetically encoded near-infrared fluorescent calcium ion indicator. Nat. Methods 16, 171-174 (2019).

21. Zhao, Y. et al. An Expanded Palette of Genetically Encoded Ca2+ Indicators. Science 333, 1888-1891 (2011).

22. Carlson, H. J. \& Campbell, R. E. Mutational analysis of a red fluorescent protein-based 
calcium ion indicator. Sensors 13, 11507-11521 (2013).

23. Cranfill, P. J. et al. Quantitative assessment of fluorescent proteins. Nat. Methods 13, 557-562 (2016).

24. Molina, R. S. et al. Understanding the Fluorescence Change in Red Genetically Encoded Calcium Ion Indicators. Biophys. J. 116, 1873-1886 (2019).

25. Inoue, M. et al. Rational design of a high-affinity, fast, red calcium indicator R-CaMP2. Nat. Methods 12, 64-70 (2015).

26. Kerruth, S., Coates, C., Dürst, C. D., Oertner, T. G. \& Török, K. The kinetic mechanisms of fast-decay red-fluorescent genetically encoded calcium indicators. J. Biol. Chem. 294, 3934-3946 (2019).

27. Carlson, H. J. \& Campbell, R. E. Circular permutated red fluorescent proteins and calcium ion indicators based on mCherry. Protein Eng. Des. Sel. 26, 763-772 (2013).

28. Akerboom, J. et al. Genetically encoded calcium indicators for multi-color neural activity imaging and combination with optogenetics. Front. Mol. Neurosci. 6, 2 (2013).

29. Molina, R. S. et al. Blue-Shifted Green Fluorescent Protein Homologues Are Brighter than Enhanced Green Fluorescent Protein under Two-Photon Excitation. J. Phys. Chem. Lett. 8, 2548-2554 (2017).

30. Podgorski, K. \& Ranganathan, G. Brain heating induced by near-infrared lasers during multiphoton microscopy. J. Neurophysiol. 116, 1012-1023 (2016).

31. Dana, H. et al. High-performance calcium sensors for imaging activity in neuronal populations and microcompartments. Nat. Methods 16, 649-657 (2019).

32. Patriarchi, T. et al. Ultrafast neuronal imaging of dopamine dynamics with designed genetically encoded sensors. Science 360, eaat4422 (2018). 
33. Shen, Y. et al. Genetically encoded fluorescent indicators for imaging intracellular potassium ion concentration. Commun Biol 2, 18 (2019).

34. St-Pierre, F. et al. High-fidelity optical reporting of neuronal electrical activity with an ultrafast fluorescent voltage sensor. Nat. Neurosci. 17, 884-889 (2014).

35. Ai, H.-W., Baird, M. A., Shen, Y., Davidson, M. W. \& Campbell, R. E. Engineering and characterizing monomeric fluorescent proteins for live-cell imaging applications. Nat. Protoc. 9, 910-928 (2014).

36. Gross, L. A., Baird, G. S., Hoffman, R. C., Baldridge, K. K. \& Tsien, R. Y. The structure of the chromophore within DsRed, a red fluorescent protein from coral. Proc. Natl. Acad. Sci. U. S. A. 97, 11990-11995 (2000).

37. Tsien, R. \& Pozzan, T. Measurement of cytosolic free Ca2+ with quin2. Methods Enzymol. 172, 230-262 (1989).

38. Drobizhev, M., Molina, R. \& Hughes, T. Characterizing the Two-photon Absorption Properties of Fluorescent Molecules in the 680-1300 nm Spectral Range. BIO-PROTOCOL 10, e3498 (2020).

39. Abdelfattah, A. S. et al. Bright and photostable chemigenetic indicators for extended in vivo voltage imaging. Science 365, 699-704 (2019). 


\section{Supplementary information}

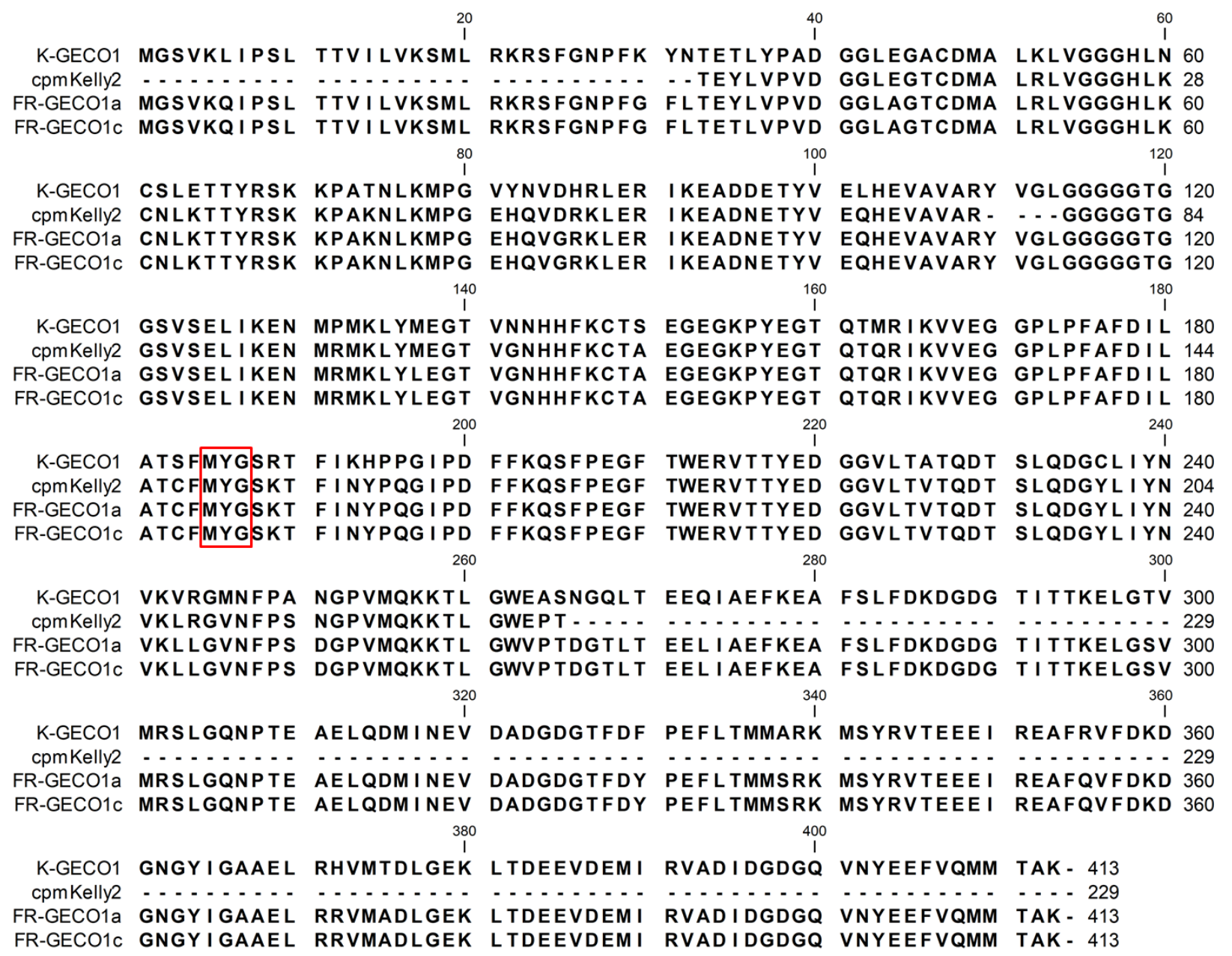

Supplementary Figure 1. Sequence alignment of K-GECO1, mKelly2, FR-GECO1a, and

FR-GECO1c. Chromophore-forming residues are indicated by a red box. 

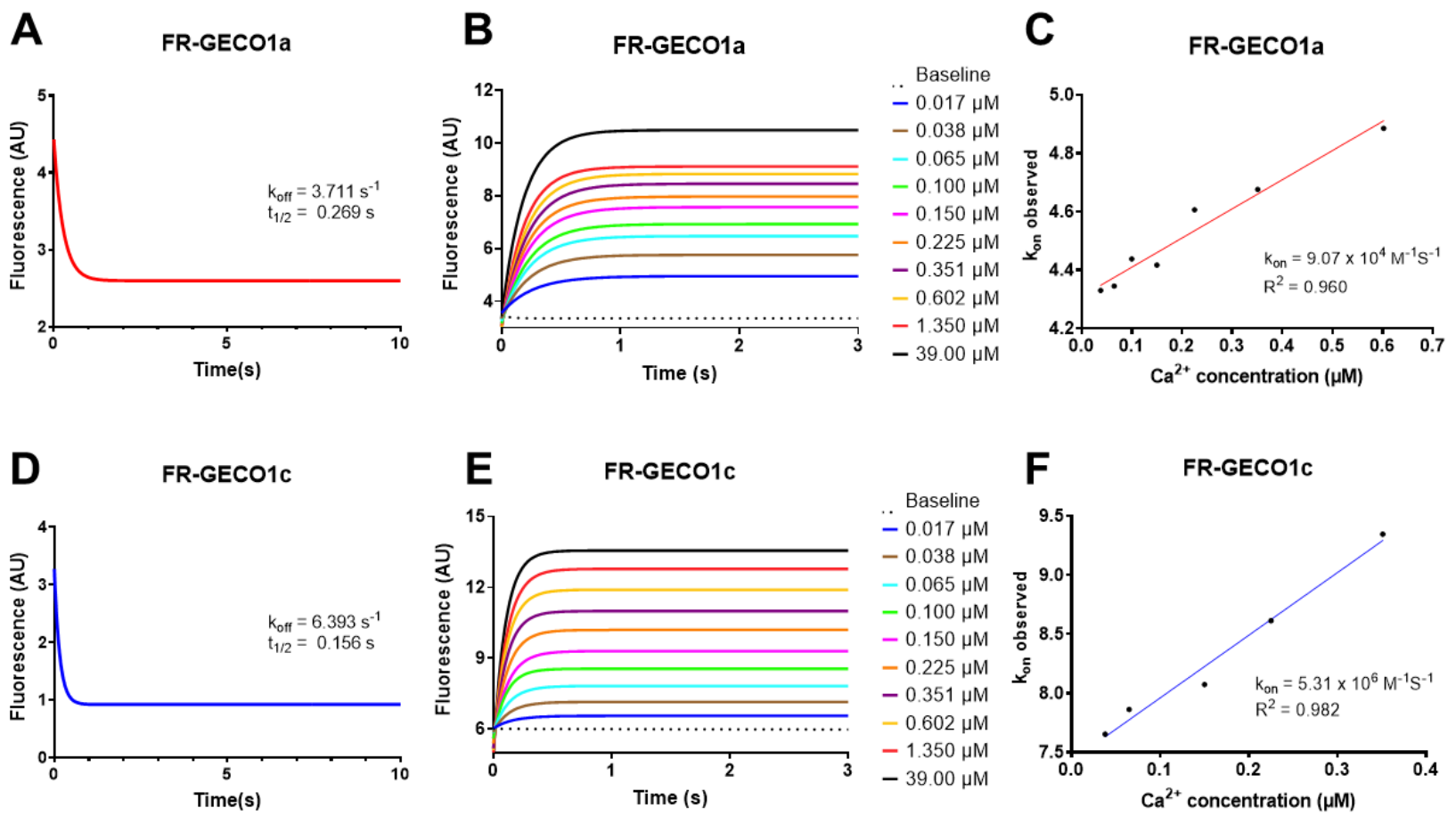

Supplementary Figure 2. Kinetics of FR-GECO1a and FR-GECO1c purified proteins. $\mathrm{Ca}^{2+}$ dissociation kinetics of FR-GECO1a (A) and FR-GECO1C (D). $\mathrm{Ca}^{2+}$ association kinetics of FR-GECO1a (B) and FR-GECO1c (E). Observed rate constants plotted as a function of $\mathrm{Ca}^{2+}$ concentration for FR-GECO1a (C) and FR-GECO1c (F). 

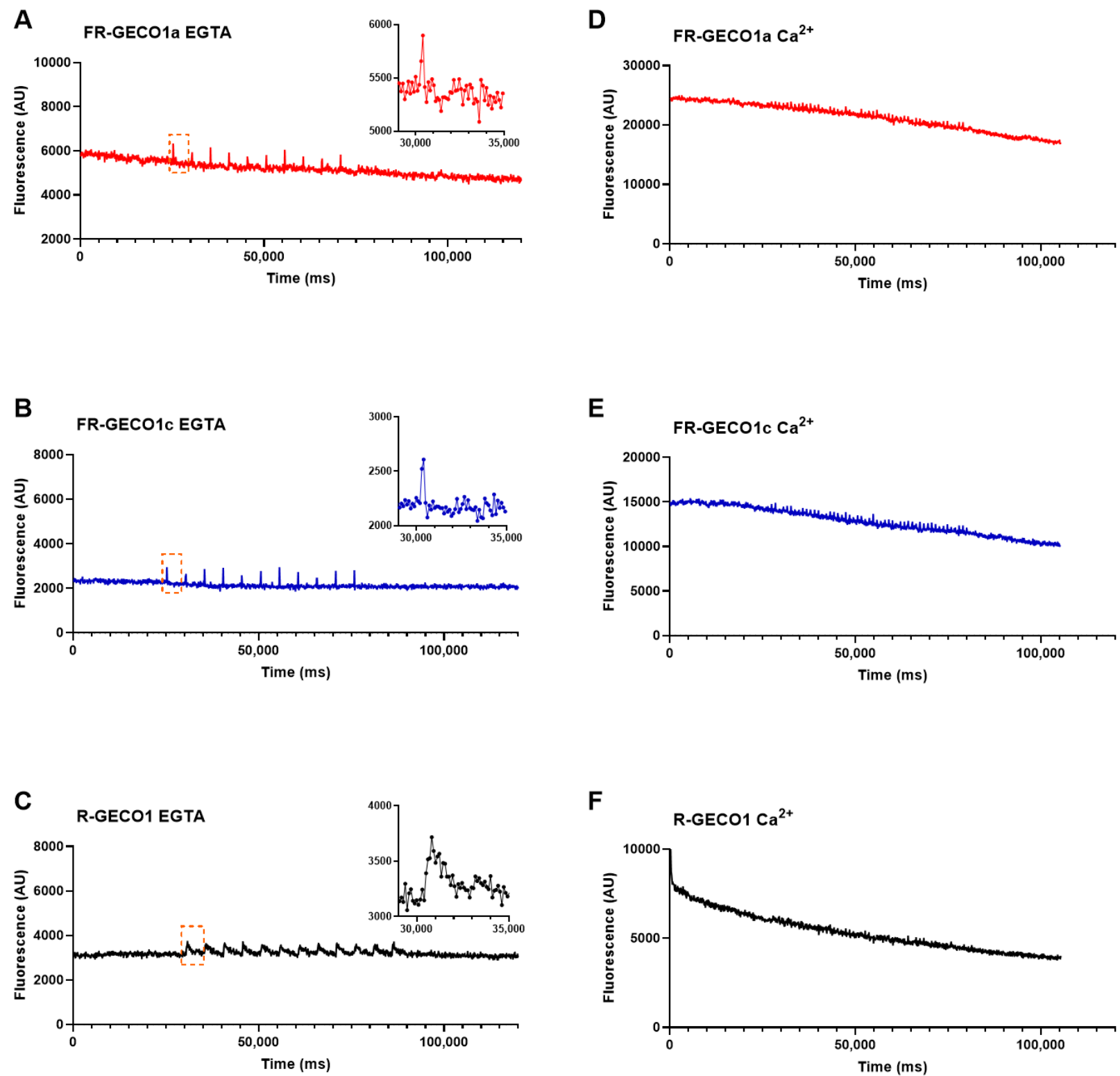

Supplementary Figure 3. In vitro photoactivation of FR-GECO1a, FR-GECO1c, and R-GECO1 purified proteins. Representative fluorescence responses of FR-GECO1a (A), FR-GECO1c (B), and R-GECO1 (C) to $50 \mathrm{~ms}$ of pulse $(0.5 \mathrm{~Hz})$ illumination with a $488 \mathrm{~nm}$ $\left(0.71 \mathrm{~W} / \mathrm{cm}^{2}\right)$ laser and constant illumination with a $561 \mathrm{~nm}\left(3.70 \mathrm{~W} / \mathrm{cm}^{2}\right)$ laser in the absence of $\mathrm{Ca}^{2+}$ (MOPS-EGTA buffer). Insets: zoom-in view of single photoactivation event traces. Representative FR-GECO1a (D), FR-GECO1C (E), and R-GECO1 (F) fluorescence responses to $50 \mathrm{~ms}$ of pulse $(1 \mathrm{~Hz})$ illumination with a $488 \mathrm{~nm}\left(0.71 \mathrm{~W} / \mathrm{cm}^{2}\right)$ laser and constant illumination with a $561 \mathrm{~nm}\left(3.70 \mathrm{~W} / \mathrm{cm}^{2}\right)$ laser in the presence of $\mathrm{Ca}^{2+}$ (MOPS-CaEGTA buffer). 
bioRxiv preprint doi: https://doi.org/10.1101/2020.11.12.380089; this version posted November 15,2020 . The copyright holder for this preprint (which was not certified by peer review) is the author/funder, who has granted bioRxiv a license to display the preprint in perpetuity. It is made available under aCC-BY-NC-ND 4.0 International license.

Supplementary Table 1. Key mutations of far-red FPs grafted onto existing red GECls

\begin{tabular}{|l|l|l|l|}
\hline Red GECI & Far-Red FP & Key mutations grafted* & Result \\
\hline R-GECO1 & E2-Crimson & $66 F, 197 Y$ & Non-fluorescent \\
\hline CH-GECO1 & RDSmCherry & $161 G, 163 G$ & No spectral shift \\
\hline K-GEC01 & mCardinal & $41 G$ & Non-fluorescent \\
\hline
\end{tabular}

${ }^{*}$ Residue numbering according to FP 
bioRxiv preprint doi: https://doi.org/10.1101/2020.11.12.380089; this version posted November 15,2020 . The copyright holder for this preprint (which was not certified by peer review) is the author/funder, who has granted bioRxiv a license to display the preprint in perpetuity. It is made available under aCC-BY-NC-ND 4.0 International license.

Supplementary Table 2. Mutations accumulated during engineering of FR-GECOs.

\begin{tabular}{|l|l|}
\hline Name & Mutations (ckkap Linker cpmKelly2 CaM) \\
\hline $\mathbf{0 . 1}$ & Template \\
\hline $\mathbf{0 . 2}$ & $0.1+$ K30G Y31F N32L \\
\hline $\mathbf{0 . 3}$ & $0.2+(\mathrm{M} 1 \mathrm{~V})$ D 85 G N251D R355Q H372R \\
\hline $\mathbf{0 . 4}$ & $0.3+$ E263V \\
\hline $\mathbf{0 . 5}$ & $0.4+$ R244L \\
\hline $\mathbf{0 . 6}$ & $0.5+$ Q268R Q273L \\
\hline $\mathbf{0 . 7}$ & $0.6+$ L6Q M137L N266D \\
\hline $\mathbf{0 . 8}$ & $0.7+($ V1M) T299S A338S T375A \\
\hline $\mathbf{0 . 9}$ & $0.8+$ E44A F330Y \\
\hline $\mathbf{1 a}$ & $0.9+$ R268T \\
\hline $\mathbf{1 c}$ & $1 \mathrm{a}+$ Y35T \\
\hline
\end{tabular}


Supplementary Table 3. In vitro 2P comparison of FR-GECOs with other red GECls.

\begin{tabular}{|c|c|c|c|c|}
\hline Red GECI & $\begin{array}{l}2 \mathrm{P} \text { brightness of } \\
\mathrm{Ca}^{2+} \text {-saturated form } \\
\text { of the anionic } \\
\text { chromophore }\left(\varphi \times \sigma_{2}\right) \\
\mathrm{GM}\left(\text { at } \lambda_{2 \mathrm{P}, \max }\right)\end{array}$ & $\begin{array}{l}2 \mathrm{P} \text { brightness of } \\
\mathrm{Ca}^{2+} \text {-saturated form } \\
\text { of the anionic } \\
\text { chromophore }\left(\varphi \times \sigma_{2}\right) \\
\text { GM }(1200 \mathrm{~nm})\end{array}$ & $\begin{array}{l}F_{2}\left(\lambda_{2 P, \max }\right) \\
\left(\varphi \times \sigma_{2} \times \rho\right) \\
G M\end{array}$ & $\begin{array}{l}F_{2}(1200 \mathrm{~nm}) \\
\left(\varphi \times \sigma_{2} \times \rho\right) \\
\mathrm{GM}\end{array}$ \\
\hline FR-GEC01a & $20(1112 \mathrm{~nm})$ & 15 & 9.2 & 6.9 \\
\hline FR-GEC01c & $15(1112 \mathrm{~nm})$ & 11 & 7.4 & 5.5 \\
\hline R-GEC01.2 & $9.6(1044 \mathrm{~nm})$ & 0.13 & 8 & 0.10 \\
\hline CAR-GECO1 & $9.4(1060 \mathrm{~nm})$ & 0.6 & 8 & 0.54 \\
\hline K-GECO1 & $11(1068 \mathrm{~nm})$ & 1.1 & 8 & 0.83 \\
\hline jRCaMP1a & $12.4(1076 \mathrm{~nm})$ & 2.7 & 10 & 2.2 \\
\hline
\end{tabular}

${ }^{*}$ Data for R-GECO1.2, CAR-GECO1, K-GECO1, and jRCaMP1a from Molina et al. ${ }^{24}$ 
bioRxiv preprint doi: https://doi.org/10.1101/2020.11.12.380089; this version posted November 15,2020 . The copyright holder for this preprint (which was not certified by peer review) is the author/funder, who has granted bioRxiv a license to display the preprint in perpetuity. It is made available under aCC-BY-NC-ND 4.0 International license.

Supplementary Video 1. Performance of FR-GECO1a in cultured neurons.

Supplementary Video 2. Performance of FR-GECO1c in cultured neurons. 